\title{
Going, going, but not gone: the impact of social and technological influences on the Australian Deaf community
}

\author{
By Ingrid van Steenwyk
}

Australia's Deaf community, whose members consider themselves part of a distinct sociocultural minority group identified by their use of Australian Sign Language (Auslan), is experiencing significant and rapid change. Recent social and technological influences such as cochlear implants, telecommunications technology, mainstreaming and the closure of Deaf Clubs are changing the way Deaf people communicate, socialise and identify. Some research suggests that these influences combined with advances in medical care and genetics have the potential to wipe out deafness altogether, taking with it the entire community, its unique culture and one of the world's few native signed languages (Johnston 2004). Through some aspects of ethnographic field work such as focus groups and participant observation, this article presents an exploration of the Australian Deaf community. Specifically, it examines how and why the community has changed over recent years, and where it may be headed within a social context that favours dominant hearing ideologies associated with medical and scientific perspectives on deafness. In drawing on the collective memory and collective identity of Deaf people, this study reveals the complexity of the Australian Deaf community, illustrating how it re-affirms itself through its agency and how recurring themes of power, control and dominance play out in the lives of Australian Deaf people today. While demonstrating the strength and resilience of a community galvanised by a shared history, language, identity and world view, this study also draws out the Australian Deaf community's unease about the future, signified by feelings of loss, disconnection and a weakening sense of Deaf identity. This study further uncovers the importance of "place" for the Deaf community and feelings of displacement as the community changes, and as Deaf Clubs, which represented feelings of home, identity and control, disappear from the Deaf landscape. Conclusions drawn from this study infer the need for consideration of the role of the Deaf community, as well as issues of Deaf leadership and place in the development of public policy on education, medical intervention and other policy areas affecting the wellbeing and future of Deaf people.

\section{Introduction}

In 2004, Australian sign language researcher Trevor Johnston claimed that one of Australia's unique cultural and linguistic minority groups - the Deaf community could become extinct in half a lifetime. His paper "W(h)ither the deaf community?" (Johnston 2004) offered compelling evidence that suggested the size of Australia's Deaf community had been declining over recent decades, and that this decline was expected to accelerate. Improvements in medical care, mainstreaming in schools, technological developments such as cochlear implants and advances in genetics were contributing to the declining prevalence and incidence rates of deafness. This, he predicted, could effectively bring an end to the Deaf community in Australia, taking 
along with it one of the world's few native signed languages, Australian Sign Language (Auslan).

As someone with an interest in and familiarity with the Deaf community, this news came as quite a shock to me. I have been a student of Auslan and have worked in a non-governmental organisation that operates education programmes for Deaf children in New South Wales, Australia. I also have friends in the Australian Deaf community. These experiences and relationships have led to an ongoing interest in the social, cultural and political issues affecting the Deaf community. The thought of losing a community, language and culture prompted several questions. How does the Deaf community feel about this? Do they want to do something about it? Could they do anything about it? If so, what will they do? Will this forecast change the community? What will the Australian Deaf community look like in 10 years' time, 20 years' time?

I soon realised that investigating concerns about the future of the Deaf community in Australia required an exploration of both the present and the past. Following the convention of many writers of Deaf community and Deaf culture, I use the capitalised "Deaf" here to refer to those born deaf and who identify with the language, community and culture of the Deaf collective. Lower case "deaf" refers to the audiological condition of deafness, or the larger group of individuals with hearing loss who choose not to relate to the signing Deaf community. What did it mean to be a member of the Deaf community? What is Deaf culture? Have these concepts changed over time? If so, how? An exploration of these areas provide the context to the central aim of my study which seeks to capture the voices of a community entering a critical period of change.

I explored this topic through some aspects of ethnographic research, including focus groups and participant observation. I held two focus groups, each with four Deaf people, over two weeks in July 2006. I facilitated the focus groups by leading discussion with a few prompt questions, such as "How has the Australian Deaf community changed in recent years?" and "What impact have cochlear implants had on the Deaf community?" While I do sign myself, I did not feel I was sufficiently skilled to lead the discussion without the help of interpreters, so I hired two qualified Auslan interpreters who provided the voice-overs for the discussion. As Auslan is a visual language, the focus groups were filmed in order to provide a record of all the subtleties in communication and to aid the transcription process. I also recorded the voice-overs onto audio tape in case the sound recording on the video tape was unclear. The tapes were transcribed into a script of 25,000 words and analysed thematically. While effort was made to ensure the sample group represented a range of ages, backgrounds and qualifications, it was not as diverse as I had hoped. All participants were over 26 years of age, and over half were university educated - statistics which are not representative of the Deaf community in Australia. In particular, I consider the lack of perspectives from young people to be a major drawback.

I also attended a number of events in Sydney for, or organised by, the Deaf community over the course of a year as part of my participant observation. These included a barbecue for Deaf people and hearing sign language students, the Annual General Meeting of the Australian Association of the Deaf, a $50^{\text {th }}$ birthday party of a Deaf friend, a darts night for a mixed hearing and Deaf social group and a fundraising event, "Deaf Perfect Match", for the NSW Association of the Deaf. These experiences helped me to understand better the broader cultural and social context of the Deaf 
world. Some observations and recollections from previous encounters with Deaf people were also included in my field notes.

\section{The Deaf community}

In Australia, as in other western nations today, the Deaf community is not synonymous with the deaf population. The Australian deaf population, estimated at 20,000 , consists of those who have been deafened through accident, illness or old age - people who see themselves as hearing people who have lost their hearing - as well as those deaf people who are part of the Deaf community. The Australian Deaf community, estimated at only 7,000, comprises profoundly Deaf signers as well as "Deaf-identified native hearing signers who have acquired near native fluency in signing through involvement in and identification with the Deaf community" (Johnston 1989:470-471, 2004:367).

The Australian Deaf community, like other Deaf communities, is viewed by its members as a group, similar to the way Barth (1969) describes an ethnic group. According to Barth, the existence of an ethnic group must be affirmed socially and ideologically through the general recognition that it is culturally distinctive. Further, this cultural distinctiveness has to be related to social practices such as marriage, language or work (Eriksen 2001:263). In the case of the Deaf community, it is the use of sign language that most obviously represents cultural distinctiveness. Sign language (specifically Auslan in the Australian Deaf community) is used as a mark of group membership in the home, at special events, in various Deaf Clubs and some schools. In fact, Auslan was officially recognised as a community language in Australia in 1987. Described as "the cement that binds the community together" (Johnston 1989:471) sign language is also used by the Deaf community to exclude others - many Deaf use a different kind of signing with hearing people than they do with Deaf people.

There are other elements of cultural distinctiveness that reinforce the Deaf community's existence as a perceived group. These elements relate to Deaf identity and assume behavioural, attitudinal and political status. To identify as a member of any Deaf community - to be "Deaf" - has a number of connotations. As well as having deep respect for and skill in sign language, being Deaf also means sharing an orientation towards visualist bodily practices. In fact, many Deaf people prefer to describe themselves as "people of the eye", a description first used by the American Deaf leader George Veditz in 1910 (Baynton 1996:10, cited in McKee 2001:17). Identifying as a member of the Deaf community may also include being resentful of hearing paternalism, and a belief in the rights and abilities of Deaf people to control their own lives. Deaf people may also devalue speech and lipreading and believe they have a right to affiliate with their own (Glickman 1996:127). Members of the Deaf community, including those of the Australian Deaf community, see deafness from a culturo-linguistic perspective - that is, seeing their existential situation primarily as that of a language minority rather than a disabled group (Ladd 2003:15). This perspective contrasts with the dominant medical model of deafness, which is based on a deficit theory and regards deafness as a pathological absence of hearing, placing the onus on the individual to adapt to society rather than vice versa (Hubert 2000, Senghas and Monaghan 2002). 
Let me set this current situation against the impact of historical attitudes towards the Deaf community. Attitudes towards d/Deaf people and sign language, which have fluctuated depending on the political and social climate of the time, have greatly impacted upon the creation and sustainability of Deaf communities worldwide. For most of the eighteenth century in France, for example, Deaf people were perceived positively. Deaf people and sign language became the hallmark for increased speculation about the nature of humans and of language by philosophers emerging from the Enlightenment (Ladd 2003:104-105). Evidence suggests that Deaf people were not segregated from society during this period but in fact received an unprecedented level of public attention. Deaf schools were seen as model schools, and all teacher-training institutes were encouraged to partner with them and learn from their methods (Carty 2006b). Deaf people were also involved in political movements and fought in the revolutionary army (Ladd 2003). Rosenfeld (2005) suggests that sign language was used to foster a distinctive revolutionary political vision where educated signing Deaf people were painted as the "new men" of the revolution, and their language was upheld as uncorrupted and pure - the language of the future. The positive perception of Deaf people during this period, combined with the establishment of Deaf schools followed by Deaf communities, led to the development of a larger collective Deaf identity and a network of national and international Deaf communities (Ladd 2003:109).

Once the French revolution passed, however, attitudes towards Deaf people and their language changed. Guided by the belief that nature could be improved by reason, it was felt that teaching Deaf people to speak represented a necessary stage in their evolution to full human status (Ladd 2003:114). This view was linked with the development of colonialism, which constructed essentialist similarities between natives and $\mathrm{d} /$ Deaf people. Both groups were perceived to be unable to speak European languages and to use gesture and sign to communicate - and were thus described as "savages" in a belief system which constructed a hierarchy of civilisation, ranging from civilised European men at the top down to savages and animals (Mirzoeff 1995:68, cited in Ladd 2003:114). Once dehumanised in this way, $\mathrm{d} /$ Deaf people were categorised, along with other "savages", as targets for the civilising mission of the emerging imperial nations (Ladd 2003:115). By saving their souls and thereby orienting them towards society's dominant values, hearing people could animate and endow with intellect these blocks of "unchiselled marble" or "statues" (Lane 1984:34) as the d/Deaf were described.

Movements such as evolutionism and eugenics that took hold in the second half of the nineteenth century in Europe continued to shape negative attitudes towards sign language, and created a social climate that favoured restrictive oralist approaches (the exclusive use of lipreading and speech) over manual approaches (the use of sign language) when teaching d/Deaf children. Political influences, such as the republican ideology that dominated France at the time, reinforced this oralist climate. Politicians believed it was necessary to unify the French people by forcing them to become culturally homogenous. $d$ /Deaf people were forced to use the national language of spoken French, as opposed to French Sign Language, as this was the only way they could become fully human, civilised and thus French (Quartararo 1993:40). The trend persisted amongst other European nations, such as Germany and Italy whose governments were also in the process of forging a common culture.

It was within this context that one of the most famous turning points in the history of Deaf education occurred. In 1880, delegates at the Second International Congress of 
Educators of the Deaf in Milan, Italy (where all but one delegate was hearing) passed a resolution declaring the superiority of the oral method over the manual approach when teaching Deaf children. The resolution resulted in the banning of sign languages in classrooms of schools for the Deaf and the beginning of the spread of oralism across Europe. This uniform shift towards oralism was met with outrage by many, and was described in one French publication as a method of "violence, oppression, obscurantism, charlatanism which only makes idiots of the poor deaf-mute children" (Lane 1984:404). The Milan resolution had dire consequences for the lives of Deaf people. Many Deaf teachers and professors were fired from their posts, and as the oralist method failed to produce the results it promised, Deaf people around the world spiralled towards a social underclass characterised by lack of education, unemployment and low status.

\section{Collective memory and collective identity}

Historical events such as the Milan resolution, described above, have helped set up a binary relationship between Deaf and hearing people. For Deaf people today both in Australia and elsewhere, the Milan resolution has become part of Deaf folklore, and is remembered as a devastating event that not only threatened the Deaf community but triggered the worldwide decline of Deaf people towards a social underclass. The Milan resolution, and the significance attributed to it, constitutes a "collective memory" in the sense that Novick (1999) uses this term: more than just historical knowledge shared by a group, it is a phenomenon seen from a single committed perspective that expresses some eternal or essential truth about the group - usually tragic. The shared memory of the Milan resolution expresses the tragedy of the destruction of a vibrant, healthy and respected Deaf community by the hearing majority. At a deeper level, the Milan resolution may constitute one primary moment in the ongoing experience of the dominance, control and power that hearing people have had, and continue to have, over the lives of Deaf people. For example, during discussion about current leadership in the Australian Deaf community, one focus group participant stated that fallout from the Milan resolution was directly responsible for the lack of current educated Deaf leaders in Australia today.

Novick (1999) states that once established, a collective memory comes to define a collective identity for the group. The Deaf community is re-affirmed through its shared experience of domination by the hearing community. It also fosters a collective identity that emphasises the positive sense of being "Deaf": access to a unique and natural language, a culture, and a national and international community. This provides Deaf people with agency, allowing them to resist the control exercised over them and to enforce power over their own affairs. Certainly the sense of Deaf pride constitutes a collective memory and has become well recognised as a feature of the collective identity of Deaf people. It is borne out in the plethora of local, national and international Deaf organisations, as well as events such as National Week of Deaf people, all of which aim to improve the rights of Deaf people and celebrate the achievements of their community.

My fields notes taken at the NSW Association of the Deaf's "Deaf Perfect Match" fundraiser illustrate this positive sense of being Deaf for members of the Australian Deaf community:

Arms and hands swirled through the air and animated facial expressions characterising the conversations of the Deaf created a mood high in energy 
and spirit. The show itself followed the format of the original television programme, Perfect Match, only conducted in Auslan. The contestants were Deaf, and being part of a small community, most were known by the audience, which was the cause of much amusement. The audience seemed to thoroughly enjoy the show, showing support for certain contestants and cheering wildly when a "match" was made. While the tone of the show was light-hearted and fun, it was punctuated by more serious episodes. During breaks, for example, organisers appealed to the audience for financial support for various activities designed to strengthen both the Australian and global Deaf communities. These included the involvement of four Deaf Australians in the $4^{\text {th }}$ World Deaf Youth Camp in Spain in 2007 and projects aimed at developing Deaf communities in Kosovo. This was a space where Deaf people, their culture and language dominated, effectively reversing traditional power relationships and leaving hearing people who did not sign in the minority. The event represented a community that was passionate, strong, organised, aware and independent. Being Deaf was not something to be hidden away or ashamed of, but something to be cherished and proudly embodied.

Despite this collective strength of the Deaf community, notions of oppression, control, power, and dominance by the hearing community emerge time and again in the collective memory of Deaf people, and continue to play out as the community and culture experiences significant change today. Whether it is through education, technology or social practices, the voices of Deaf people have been and continue to be overpowered. Though the community endeavours to demonstrate resistance, analysis from my focus groups indicates that there is a new sensibility emerging in collective narratives. This sensibility is expressed by referring to a phase of weakening and fragmentation of the Deaf community where the overwhelming tone conveys an uncertain future. Using clearly oppositional language of "we/us" for Deaf people and "they/them" for hearing people, one focus group participant stated:

There's another part of me that feels like we've lost our power. We're disempowered and we can't fight like we used to be able to. Before we were just able to make things happen, whereas now we might say things to people but they don't take any notice of us. We're disempowered, we've lost something. And it's not about what we want but what they want for us. And we've got to fit in with them, rather than them fitting in with us.

\section{Preoccupations of the Australian Deaf community}

\section{Closure of Deaf Clubs}

Sydney's famous Stanmore Deaf Recreation Club, which existed from 1975 to 1993, was a popular meeting place for the Deaf community. It was the home to many Deaf sporting and interest groups, and helped create a strong, unified Deaf community and a positive sense of identity for Deaf people. The decision to close the Club was made, according to some, without the involvement of Deaf people and is frequently singled out in the collective memory of Deaf people as an event at which their voice was overpowered by that of the majority community. Frequently referring to it as their "home" and the "hub" for Deafness, many sections of the Deaf community were devastated at its closure. One focus group participant stated:

Stanmore was then closed by the Deaf Society's Board who were all hearing. And I felt that they should have asked or included Deaf people in 
the discussions, because the club was run by Deaf people, but unfortunately, under the guise of the Deaf Society, which was run by hearing people. We felt like puppets. Since its closure I think it's damaged the Deaf community.

The closure of the Deaf Club at Stanmore has resulted in significant changes in the way the Deaf community socialises, and in the transmission of culture and language from generation to generation. Focus group participants lamented that without a central home for Deaf people provided by a place like Stanmore, where people could share news, network and socialise, and children could learn from other Deaf role models, the community will weaken.

With the closure of the Deaf Clubs not only in Sydney but also in other Australian states, Deaf people have become even more concerned about the influence of the culture, attitudes and behaviour of hearing people upon Deaf people. In particular, some focus group participants worried about young Deaf people "drifting" towards the hearing world and in doing so, losing their sense of Deaf identity:

There are a lot of people who have never experienced that sense of Deaf identity that we had, that existed in the past. And is it that Deaf people are becoming effectively like hearing people? They are not identifying as Deaf, they're not linked to the community.

Clearly as younger Deaf people are subsumed by the mainstream culture, what could be viewed as normal social change is perceived by members of the Australian Deaf community as a threat to their future sustainability.

\section{Cochlear implants}

The development of the cochlear implant, and the discourse associated with it, further reinforce a collective memory for Deaf people that evokes a notion of dominance by the majority community. Cochlear implants are surgically implanted devices that direct electrical impulses to the cochlea to stimulate hearing. The rates of cochlear implantation of severely and profoundly deaf children in Australia are reported to be very high and increasing rapidly (Johnston 2004). The media regularly herald cochlear implants as "magical cures" and "revolutionary", and implants are credited as "helping deaf people become part of the hearing world", suggesting that the only way deaf children can lead a viable life is by being implanted and hence normalised (Power 2005:455). This perspective, however, is largely contested by many Deaf people. Since the invention of cochlear implants the Deaf community has expressed concern over the effects of the device, including short term physical consequences such as facial paralysis and infection. Others object to the use of cochlear implants on the grounds that they cause conflict with the social, cultural and linguistic beliefs of the signing community. Cochlear implants are designed to make Deaf people as close to hearing people as possible, and are often associated with strict oral-only educational programmes that prevent the use of sign language, instead encouraging deaf children to use the hearing techniques of listening and speaking to communicate. Other objections to cochlear implants have included accusations of cultural genocide by doctors (Christiansen and Leigh in Padden and Humphries 2005:167) - a discourse that reinforces and resonates with the collective memory of the Milan resolution of 1880 as a "tragic event".

Many focus group participants had strong negative feelings towards cochlear implants. They expressed concern over pressure from intellectuals of the medical community to test for deafness and implant children, describing this pressure as 
"violating", "nauseous" and "dislocating". Specifically, focus group participants indicated that cochlear implants have been implicated in creating and reinforcing divisions within the Deaf community.

I think for a lot of people, when they're implanted, it changes their attitude. They think that they can hear better. I see a lot of arguments in the playground. People say "oh, I'm better than he is" or "she's better than her" because of the implant. And when we have the Deaf annual camp for kids, often those children who are implanted form their own separate group.

A major concern regarding cochlear implants, then, is the potential threat they bring of undermining both the cohesion and the collective identity of the Deaf community. Some focus group participants believed that due to the rise of cochlear implants, an increasing number of Deaf people are "choosing the oral route". This means they choose speech and hearing to communicate rather than sign language, and they choose not to identify as part of the Deaf community (they may in fact reject it) but associate only with the wider hearing community. It is feared that this process of assimilation may threaten the continued existence of the Deaf community.

\section{Mainstreaming}

The recent shift in educational philosophy, initiated in the 1980s, has seen the phasing out of special schools for Deaf children in favour of mainstreaming. Mainstreaming involves the integration of $\mathrm{d} /$ Deaf children into local schools where they are provided with assistance from itinerant teachers of the deaf, and perhaps sign language interpreters if they use sign language. This approach is consistent with the social perspective on deafness which advocates for the "normalisation" of disability. However, the benefits of mainstreaming have been contested by sections of the Deaf community, who argue that the approach represents ways in which their lives are once again subject to the controlling agenda set by intellectuals from the dominant majority. Focus group participants made regular reference to the role of mainstreaming in fragmenting and weakening the Deaf community. According to one participant, mainstreaming produces hierarchies between Deaf children, unlike Deaf schools, which facilitated a strong and often lifelong bond between Deaf people. Mainstreaming contributes to the distortion of Auslan and the use of non-traditional communication techniques, eventually working to dilute and undermine the community.

When kids are mainstreamed in school you see the young kids and they mix more with hearing people. They go off, that one can speak well, they can mix with a hearing person. If the other kid can't speak so well, they feel more stupid and isolated because they can't speak as well as the others.

Focus group participants raised concerns over the emotional effect of mainstreaming Deaf children, which can produce feelings of isolation. One participant admitted that although he had been integrated successfully into a mainstream high school, he spent some of his time feeling "suicidal". Clearly, the voice of Deaf people is being overpowered by that of the dominant majority, reinforcing a collective memory of oppression and disempowerment, and reiterating the creation of a binary opposition between hearing and Deaf people.

Who are these hearing people, these hearing professionals, these teachers, these doctors, my parents? These people who made me think I was hearing? These people who had no experience of being Deaf... And I felt like, I can't believe it. I've been ripped off! That they made a decision on my behalf. 


\section{Telecommunications technology}

Technology that enhances visualism is generally welcomed by Deaf people. SMS "texting" via mobile phones and email, for example, allow Deaf people to use visual technology that frees them from having to meet face-to-face to share information, or to rely upon an intermediary to communicate messages. The use of this technology by Deaf people has resulted in increased social networks and has been found to improve literacy, independence and decision-making in Deaf adolescents (Akamatsu et al 2006). Further, many Deaf people believe that the development of such telecommunications technology has led to a more "even playing field" between hearing and Deaf people, reducing the stigma of "specialness" and giving them for the first time a common language with hearing people (Power and Power 2004).

The internet in particular is creating new kinds of meeting places and work areas and the possibilities of new types of relationships across space and time (Keating and Mirius 2003:693). Through the use of a small webcam, Deaf individuals can communicate visually with one another over ordinary telephone lines. This is revolutionary because it means they can use sign language to communicate across long distances. Focus group participants spoke positively about how this type of technology can increase connections between Deaf people who are geographically dispersed throughout the hearing community.

Some Deaf people, however, worry about the intrusiveness of enhanced telecommunications technology, citing privacy issues as a concern, particularly with new computer-mediated visual telephone technology. Being visually available transforms aspects of what you do before you say "hello" or accept an incoming call (Keating and Mirius 2003:699). A more general concern resulting from the increased sophistication of telecommunications technology is related to the demise of important social hubs such as Deaf Clubs. As people are no longer required to meet face-to-face to communicate or socialise, Deaf Clubs become redundant. The very capacity of this technology to make face to face communication unnecessary is celebrated by some, and seen as destructive to the community by others. As explained in the section above, the closure of Deaf Clubs leads to fewer visible role models for Deaf children, and less cross-generational mixing. It also means that there is less opportunity for the vital transfer of Deaf culture, history and language between Deaf people. Therefore the use of such technology also leads to a less homogenous community and interferes with the customary way in which Deaf culture is passed on from generation to generation. One focus group participant explained:

You get younger people who get together, and they have their technology. If there's a big event [Deaf social event] they don't bother going, they just party in their own little group.

\section{A sense of place}

Close analysis of the discussion from my focus groups suggests that the external factors currently influencing the Australian Deaf community may also in fact be eroding - in some cases destroying - the community's sense of place. Memmott (1979) states that bonds between individuals (or social groups) and places constitute part of the personal identity of those individuals (or the identity of the social group). Thus people can be seen to be dependent upon the concept of place for their selfidentity and social identity, just as places are dependent upon people for their identity 
(Memmott and Long 2002:40). Place therefore creates identity, home, power and connection - and is heavily linked to the construction of self. For the Deaf community, a sense of place is most obviously represented in the form of Deaf Clubs where Deaf people come together and share a physical space. However, a sense of place is never simply physical. Casey (1996:9) contends that place is "the most fundamental form of embodied experience". With the disappearance of Deaf Clubs and the rapid destruction of their sense of place, my study reveals the Australian Deaf community's sense of anxiety, sadness, loss and displacement.

Sydney's famous Stanmore Deaf Club is remembered as a popular social outlet for Deaf people. But Deaf Clubs in general represented much more than simply a place to come together. The physical buildings of Deaf Clubs have formed an important part of the collective memory and identity of Deaf people. They have taken shape as socially meaningful and identifiable spaces to which a historical dimension is attributed. Memories of the Deaf Club are infused with nostalgia and affection, and are continuously reflected in the narratives of Deaf people today - especially as Deaf Clubs disappear.

The relationship between place, people and identity is particularly meaningful within the context of Deaf people and Deaf Clubs. Most Deaf people are born into hearing families who do not sign and are unfamiliar with the ways of the Deaf community. They therefore acquire their Deaf culture, language, norms and values - and thus their Deaf identity - from different sources, including Deaf Clubs. The identity that Deaf people ascribe to themselves largely occurs through the Club and their community. For many Deaf people who have been brought up in hearing families, initial contact with Deaf Clubs does not occur until adolescence or adulthood. For some, this experience is seen as a significant turning point in their life as it enables them to recognise a hitherto submerged experience as a socially shared one. It may represent the discovery of their "real" identity and true "home". One focus group participant recalled his first experience, at age 16, of Stanmore Deaf Club: "I learnt so much there. The Deaf Club was where I was born again, so to speak. Life started there for me."

Like the family home, Deaf Clubs allow space where the routines of existence can be performed, relatively free from external surveillance and hence offering a sense of autonomy (Dupius and Thorns 1998, cited in Noble 2005:113). Further, they are fundamental to the fashioning of identity, relationship and belonging (Noble 2005:113). For Deaf people, Deaf Clubs represent feelings of safety. They counter the negative effects of the stigmatisation of Deaf people by providing a safe haven in which deafness, as well as their natural language - sign language - is valued and nurtured as part of a positive identity rather than discredited.

Journeys of discovery in which Deaf people find their identity or home - their "place" - do not only occur within the physical space of Deaf Clubs. One focus group participant, who was deaf but had grown up "as a hearing person" (using oral methods such as lipreading and speech to communicate) described the day he discovered what he saw as his real identity during a maths lecture at university:

There was a group of deaf people with me - all oral - one culturally Deaf but most of us oral. And there was an interpreter. I was watching the lecturer, and slowly I started watching the signing interpreter... I could see the signs, and I saw how many words were being used. I was trying to take notes... I watched the interpreter and I was catching, actually, quite a lot of 
the signs... then I was catching a lot more... And I thought, "shit, I'm Deaf!" And it really hit me. And from then on, that was it, I was Deaf!

The advancement of technology is one of the main reasons behind the disappearance of Deaf Clubs in Australia, which began in the 1980s (Breda Carty, personal communication, 2006). Carty (2006a) believes that their decline was further intensified by the growth of mainstreaming, which weakened connections between young Deaf school-leavers and dispersed Deaf people around regional areas as well as big cities.

The closure of Deaf Clubs, in particular that of Stanmore Deaf Club in 1993, left sections of the Deaf community feeling displaced. For some focus group participants, the experience was intensely and explicitly emotional, and they expressed a strong negative affect of being up-rooted and disconnected. Emotions of grief and loss were strikingly pervasive at times during our discussion: "When it closed I thought 'ok, I can keep going'. But later I realised I had lost something. I lost part of myself"; "We don't have a home... we still don't have a home." The displacement experienced by focus group participants also generated feelings of anger and injustice. One focus group participant suggested that Deaf Clubs had been "stolen" from Deaf people through an undemocratic decision made by the Deaf Society, which was comprised mainly of non-Deaf people. For Deaf people, this process represented yet another example of the dominance of the hearing majority over the Deaf community.

Leach (1999, cf. Padden and Humphries 2005:97) argues that the destruction of material space for meeting in order to make room for more metaphorical or virtual space jeopardises culture, as it takes with it the sense of belonging to a community. Deaf people's reaction to the disappearance of Deaf Clubs supports this argument. Similar feelings of grief, loss and displacement are felt in response to the decline of Deaf Schools. Like Deaf Clubs, Deaf Schools were material spaces that generated feelings of cohesion and belonging - or a sense of place - for the Deaf community. Deaf Schools allowed Deaf children to learn about Deaf culture and sign language. Importantly, they allowed Deaf children to develop a positive Deaf identity. Due to the shift in education towards mainstreaming, however, Deaf Schools have been phased out, destroying the Deaf community's sense of place, and the notion of connection between members in the process. Recalling his experiences of a Deaf School in Queensland one focus group participant noted:

We all knew each other, we grew up together. And when we left school we still knew each other. I left in 1971 and in 1979 the school actually closed and kids were sent to mainstream, different schools, government schools. Then by 1981 the school had completely closed... Before we knew each other, now we're meeting people and we go "oh, who are you? Where are you from?"

A sense of displacement seemed to permeate the focus group discussion, and was associated not only with the demise of Deaf Clubs or Deaf Schools, but also reflected more general feelings towards change in the community. This strong negative affect was interpersonal, and was shared amongst members of the group.

Sometimes I feel disconnected. I guess I know I've got my friends and community and I've got connections there but the core of the community is gone and that's painful to me. There's just this emptiness there.

The destruction of place through the disappearance of Deaf Clubs and other significant material spaces threatens the development of a positive Deaf identity, and 
thus the sustainability of Deaf culture. Older Deaf people express concern for the vulnerability of younger generations who no longer have the protection of Deaf Clubs (and through them a sense of "community") to help develop and nurture a healthy Deaf identity. One focus group participant noted:

Most of the people in my youth group - they've got no self-esteem. They've got no confidence. And I remember I got confidence from the community. That's where I learnt how to get involved. They haven't got that. They're really lacking that. Where are they supposed to get that from? Their selfimage is very negative.

\section{Conclusion}

The Deaf community in Australia has changed dramatically over the last 10 years or so. The demise of Deaf Clubs resulting from, among other things, improved telecommunications technology has not only changed the way in which Deaf people socialise but has changed the way Deaf culture and language is formed and transmitted from generation to generation. According to focus group participants, the phasing out of Deaf schools due to mainstreaming has prevented the development of a positive Deaf identity in children. The rise in the uptake of cochlear implants by people with a hearing loss has reinforced divides in the Deaf community. Some focus group participants felt these influences were contributing to a fragmentation and dilution of the Deaf community, causing fear for its future survival in the face of ongoing change. Sadly, this anxiety may be well-founded. Evidence suggests that the size of Australia's Deaf community is declining due to a range of social and technological influences. As a result, Auslan is becoming an endangered language (Johnston 2004).

The Australian Deaf community, however, is a complex community, and is not simply passively accepting changes wrought by the hearing majority. The community reaffirms itself through the agency of its members. Their history, characterised by a shared collective memory and experience of loss, displacement, domination and control - and at times trauma - has forged the construction of self, and their presentation of self in the hearing world. My experience of the Australian Deaf community suggests that it is a vibrant, proud community, rich in culture, and one that deserves a proper place in Australia's diverse society.

My research revealed the critical need for strong Deaf leadership to ensure the survival of the Deaf community. Leadership is needed to contest the dominance of rational management as well as traditional attitudes towards deafness. Further anthropological research into Deaf communities and cultures would also assist in reconceptualising certain assumptions that are apparent in policy as well as everyday attitudes - assumptions that reinforce the view that all Deaf people are disabled and that their welfare is best controlled by the hearing majority. Valuable future research topics could consider the role of the Deaf community, and issues of Deaf leadership and place in the development of public policy on education, medical intervention, genetics and other major policy areas affecting the wellbeing of Deaf people. 


\section{References}

Akamatsu, C.T., C. Mayer and S. Farrelly. 2006. An investigation of two-way text messaging use with deaf students at the secondary level. Journal of Deaf Studies and Deaf Education 11(1), 120-131.

Barth, F. 1969. Ethnic groups and boundaries: The social organisation of cultural difference. Oslo: Scandinavian University Press.

Baynton, D.C. 1996. Forbidden signs: American culture and the campaign against sign language. Chicago: University of Chicago Press.

Carty, B. 2006a. Course notes for session 7-8 for the course "Social, Language and Cultural Studies in Deafness", University of Newcastle.

--------. 2006b. Course notes for session 9 for the course "Social, Language and Cultural Studies in Deafness", University of Newcastle.

Casey, E.S. 1996. How to get from space to place in a fairly short stretch of time: Phenomenological prolegomena. In Senses of place (eds.) S. Feld and K.H. Basso, 13-52. Santa Fe: School of American Research.

Dupius, A. and D. Thorns. 1998. Home, home ownership and the search for ontological security. Sociological Review 46(1), 24-47.

Eriksen, T.H. 2001. Small places, large issues. London: Pluto Press.

Glickman, N.S. 1996. The development of culturally Deaf identities. In Culturally affirmative psychotherapy with Deaf persons (eds.) N.S. Glickman and M.A. Harvey, 115-150. Mahway, NJ: Lawrence Erlbaum Associates.

Hubert, J. 2000. Madness, disability and social exclusion: The archaeology and anthropology of "difference". London: Routledge.

Johnston, T. 1989. Auslan dictionary: A dictionary of the sign language of the Australian Deaf community. Petersham: Deafness Resources Australia.

2004. W(h)ither the Deaf community? Population, genetics, and the future of Australian Sign Language. American Annals of the Deaf 148(5), 358-375.

Keating, E. and G. Mirus. 2003. American Sign Language in virtual space: Interactions between deaf users of computer mediated video communication and the impact of technology on language practices. Language in Society 32, 693-714.

Ladd, P. 2003. Understanding Deaf culture. Cleveland: Multilingual Matters.

Lane, H. 1984. When the mind hears: A history of the Deaf. New York: Random House.

Leach, W. 1999. Country of exiles: The destruction of place in American life. New York: Pantheon.

McKee, R. 2001. People of the eye: Stories from the deaf world. Wellington: Bridget Williams Books.

Memmott, P. 1979. Landil properties of place: An ethnological study in manenvironment relations. PhD thesis, Department of Architecture, University of Queensland, St Lucia. 
Memmott, P. and S. Long. 2002. Place theory and place maintenance in indigenous Australia. Urban Policy \& Research 20(1), 39-56.

Mirzoeff, N. 1995. Silent poetry: Deafness, sign and visual culture in modern France. Princeton: Princeton University Press.

Noble, G. 2005. The discomfort of strangers: Racism, incivility and ontological security in a relaxed and comfortable nation. Journal of Intercultural Studies 26(1), 107-120.

Novick, P. 1999. The Holocaust in American life. Boston: Houghton Mifflin.

Padden, C. and T. Humphries. 2005. Inside Deaf culture. Cambridge, MA: Harvard University Press.

Power, D. 2005. Models of deafness: Cochlear implants in the Australian daily press. Journal of Deaf Studies and Deaf Education 10(4), 451-459.

Power, M. and D. Power. 2004. Everyone here speaks TXT: Deaf people using SMS in Australia and the rest of the world. Journal of Deaf Studies and Deaf Education 9(3), 333-343.

Quartararo, A,T. 1993. Republicanism, deaf identity and the career of Henri Gaillard in late nineteenth-century France.. In Deaf history unveiled: Interpretations from the new scholarship (ed.) J.V. van Cleve, 40-52. Washington: Gallaudet University Press.

Rosenfeld, S. 2005. The political uses of sign language: The case of the French Revolution. Sign Language Studies 6(1), 17-37.

Senghas, R. J. and L. Monaghan. 2002. Signs of their times: Deaf communities and the culture of language. Annual Review of Anthropology 31, 69-97.

\section{About the author}

Ingrid van Steenwyk completed a Masters Degree in Applied Anthropology at Macquarie University in Sydney, Australia, in 2007. Her thesis "Tradition, technology and transformation: The changing shape of Australia's Deaf community" examined the impact of social and technological influences on a minority community that has been diminishing in size over recent years. The project was based on ethnographic field work, including participant observation and focus groups held with members of Sydney's Deaf community. Ingrid currently works for the NSW Department of Community Services in Sydney. She can be contacted at ingridvan@hotmail.com. 